\title{
ANTIRETROVIRAL TREATMENT FOR HIV INFECTION/AIDS AND THE RISK OF DEVELOPING HYPERGLYCEMIA AND HYPERLIPIDEMIA
}

Paulo Sérgio Ramos de ARAÚJO, Ricardo Arraes de Alencar XIMENES, Carlos Frederico Costa LOPES, João Yure DUARTE, Mecleine Mendes da SILVA(1) \& Edmilda Marques CARNEIRO(2)

\begin{abstract}
SUMMARY
A cross-sectional study with internal comparison groups was conducted to describe sociodemographic characteristics, as well as verify the association between the type of antiretroviral treatment used and hyperglycemia and hyperlipidemia, with special attention to the use of HIV protease inhibitors. The data was obtained through an interview questionnaire, as well as blood and urine samples that were collected for the laboratory exams. A total of 418 patients were interviewed. 46 of these, however, met the exclusion criteria. The sample was therefore composed by 372 HIV positive patients, attended at the laboratory of the Correia Picanço State Hospital for the collection of blood, to estimate the HIV viral load and/or TCD4 cell counts from August to November 2000. The association between the variables was tested using the chi-square test and the p-value. A multiple logistic regression analysis was carried out to adjust for potential confounding factors. A greater frequency of patients with high glucose levels was observed among those making use of antiretroviral therapy without protease inhibitors, but the number of patients limited the comparisons. An association was verified between the total serum cholesterol level and the use of HIV protease inhibitors $(p=0.047)$ even after controlling for age. An association was also observed between the triglyceride levels and the use of HIV protease inhibitors, which remained after adjustment for age, sex and creatinine levels $(\mathrm{p}<0.001)$. The levels of glucose and TSH, the presence of proteinuria and the practice of physical activity were not associated either with the levels of cholesterol or with the levels of tryglicerides thus they were not confounders of the associations described.
\end{abstract}

KEYWORDS: Dyslipidemia; Hyperglycemia; AIDS; Antiretroviral therapy; HAART.

\section{INTRODUCTION}

The employment of therapeutic regimens with the combination of antiretroviral drugs has shown an impact on the survival rate of patients with acquired immune deficiency syndrome in recent years. Despite the advances obtained, starting with the earliest use of PIs in 1995 there began to emerge the first reports of alterations in the lipid metabolism related to this group of drugs. Insulin resistance, increase in plasmatic lipids, and fat redistribution have been indicated as metabolic complications related to the use of $\mathrm{ARV}^{9}$ regimens. The pathogenesis of this triad of metabolic alterations is as yet unknown. There is evidence that HIV-1 protease inhibitors have high affinity for the catalytic site of HIV-1 protease and that the latter has molecular homologies with two human proteins involved in lipid metabolism: cytoplasmic retinoid-acid binding protein type 1 (CRABP-1) and low density lipoprotein-receptor-related protein (LRP). It was then hypothesized that the binding and inhibition of CRABP-1 by the HIV1 protease inhibitors would lead to an increased apoptosis of peripheral adipocytes, with reduced fat storage and lipid release; besides that, the inhibition of LRP would exacerbate secondary hyperlipidemia, resulting in central obesity, breast fat deposition and insulin resistance ${ }^{4}$.

It has also been suggested that the components of this metabolic syndrome are not the expression of a single entity with a single cause and that several factors may potentially influence its manifestation ${ }^{18}$. A number of contributing factors have been referred, such as the duration of the ARV treatment, the duration of the HAART regimen employed, modifications in the viral load and regimen of a previous treatment.

There are as yet few studies in the literature, on the association between dyslipidemia and ARV treatment for HIV that have an analytical approach, i.e., that have a (concurrent) comparison group and perform mutual adjustment for potential confounders that may distort the magnitude of the estimated association. Furthermore, in the national literature, data on this problem are scarce, and it is not clear whether there are characteristics of our population that may influence this association. 


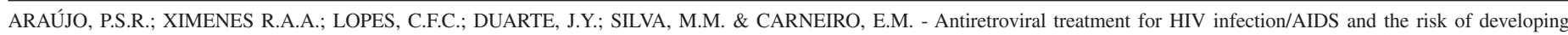
hyperglycemia and hyperlipidemia. Rev. Inst. Med. trop. S. Paulo, 49(2): 73-78, 2007.

The objective of this study was to compare the glucose levels, total cholesterol and triglycerides in three groups of patients - one group infected with the HIV without ARV treatment; another receiving ARV without PIs; and a third group of patients receiving ARV treatment with PIs - controlling for potential confounding factors.

\section{MATERIAL AND METHODS}

Study design: Through a cross-sectional study with internal control groups, we evaluated three hundred seventy-two patients (273 men and 99 women) with HIV infection in attendance at the laboratory of the Correia Picanço Hospital for a viral load count and/or CD4 cell count during the period from August to November 2000. Patients were excluded from the study if, at the time of the interview, they had eaten or drunk anything in the previous 12 hours; they had ingested alcohol within the previous 24 hours; they reported having diabetes mellitus or dyslipidemia before beginning the ARV treatment for the HIV infection.

The estimation of the sample size was based on the difference between proportions and the following parameters were considered: $\alpha$ $=5 \%, \beta=20 \%$ and power $=80 \%$. In relation to increased glycemia level, we assumed a similar frequency of that of the general population (non-diseased), that is, $7 \%^{1}$ for individuals with HIV/AIDS without ARV treatment, and $21 \%$ among the patients in ARV treatment with PIs, taking the use of ritonavir ${ }^{2}$ as the reference. Based on these estimates, the sample size calculated was 109 individuals in each group.

Concerning dyslipidemia, we considered frequencies of $28 \%$ for the group of patients who had never received a $\mathrm{PI}^{5}$, and $53 \%$ for patients receiving ARV treatment with PIs ${ }^{19}$. With these parameters, the sample size calculated was 67 individuals in each group.

We tested the association of the dependent variables (total cholesterol and triglycerides) with the main exposure - the type of antiretroviral regimen - as well as with the potential confounding factors. In order to test the associations, we employed the qui-square test, establishing a $\mathrm{p}$ value $<0.05$ as statistically significant. The adjustment for the potential confounding factors was carried out by way of a multiple logistic regression.

Data entry double with a later comparison of the two files using the VALIDATE resource. Data analysis was processed on the EPI-INFO 6.0 and Statistical Package for Social Sciences - PC.

Data collection: This study was approved by ethical committee at the Correia Picanço Hospital. Patients were referred to the laboratory of the Correia Picanço Hospital by their physicians to have their blood collected for CD4 cell count and viral load. After having received a clear explanation of the objectives of the study and having signed the informed consent, patients answered a questionnaire, supplying information regarding gender, age, marital status, place of origin, length of time with HIV infection, whether or not they had made use of ARV treatments in the previous six months, the ARV regimen used, and the practice of physical activities. Medical records were used to confirm the information given on ARV treatment. Height and weight were assessed for calculating the Body Mass Index. Blood was drawn for laboratory testing, requested either for routine evaluation or for the investigation. The levels of glucose, total cholesterol and triglycerides, as well as urea, creatinine and TSH were estimated; glucose levels were measured after 12 hours of fasting. Urine samples were taken to detect the presence of proteinuria, which could express the concomitant presence of clinical conditions such as renal failure, hypothyroidism and nephrotic syndrome. The cutoff points for the categorization of the dependent variables (glucose, total cholesterol and triglycerides) was based on the guidelines of the American Diabetes Association and NCEP III.

Standardization of techniques: All measurements were obtained under fasting conditions and just one physician performed the biochemical laboratory exams, under standardized conditions. The concentration values of glucose, total cholesterol, triglycerides and urea was determined utilizing the enzymatic method DOLES ${ }^{\circledast}$. The concentration values of LDL cholesterol were determined through the Friedwald equation. The concentration values of creatinine were determined by the colorimetric method DOLES ${ }^{\circledR}$ through the Jaffe reaction. To determine the presence of proteinuria, reagent tapes were used for urine analysis Multistix ${ }^{\circledR}$, Bayer. TSH levels were measured in a randomly chosen sub-sample of patients $(n=98)$ and were carried out through an automatized system by way of an immuno-enzymatic assay of micro-particles MEIA-Imx and MEIA-Axsym.

\section{RESULTS}

General characteristics of the study population: Over a period of four months 372 patients were studied whose characteristics are described in Table 1 . They were mainly males (73.4\%), and aged 30 to 39 years. One hundred ninety-five individuals $(52.4 \%)$ had a normal Body Mass Index (BMI) and $81.7 \%$ referred to practice no physical exercise.

In relation to the time elapsed since the serological diagnosis, one third of the patients informed that they had known about their serological status between two and five years before. Two hundred and fifty nine $(69.6 \%)$ patients had used some type of ARV medication for the HIV infection in the previous six months; $36.6 \%$ of them were treated with ARV containing PIs, 29.6\% had received ARV treatment without PIs and $30.4 \%$ had never undergone ARV treatment.

Concerning the creatinine levels $74.7 \%$ of the patients exhibited creatinine levels within the normal range and, regarding the presence of proteinuria, $86.8 \%$ were negative.

The glucose levels, total cholesterol, triglycerides and HDL cholesterol were analyzed in relation to the ARV treatment, three groups being considered: those who had never had an ARV treatment, those who received a regimen without PIs and those who had a regimen which included PIs (Table 2).

Three hundred and sixty two $(97.2 \%)$ individuals had normal glucose levels. Seven (out of ten) of those in the group with elevated glycemia were patients in ARV treatment without PIs, but the low number of patients with altered glucose levels precluded a statistical analysis. When the total cholesterol was analyzed, it was observed that most of patients (79.9\%) had normal levels. Among those who exhibited elevated levels, 51.4\% (37/72) were receiving ARV treatment with PIs. Regarding the 


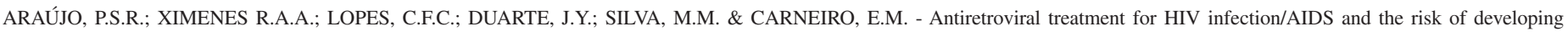
hyperglycemia and hyperlipidemia. Rev. Inst. Med. trop. S. Paulo, 49(2): 73-78, 2007.

Table 1

Distribution of HIV seropositive individuals according to biological characteristics and ARV treatment

\begin{tabular}{|c|c|c|}
\hline & $\mathrm{N}$ & $\%$ \\
\hline \multicolumn{3}{|l|}{ Age group } \\
\hline $12-29$ & 90 & 24.5 \\
\hline $30-39$ & 171 & 45.7 \\
\hline $40-49$ & 86 & 23.4 \\
\hline$>50$ & 25 & 6.4 \\
\hline \multicolumn{3}{|l|}{ Sex } \\
\hline Male & 273 & 73.4 \\
\hline Female & 99 & 26.6 \\
\hline \multicolumn{3}{|l|}{ BMI } \\
\hline Undernourished & 58 & 15.6 \\
\hline Normal & 195 & 52.4 \\
\hline Over weight & 99 & 26.6 \\
\hline Obesity & 19 & 5.1 \\
\hline Morbid obesity & 01 & 0.3 \\
\hline \multicolumn{3}{|c|}{ Time since diagnosis (months) } \\
\hline$\leq 6$ & 64 & 17.2 \\
\hline $6-12$ & 40 & 10.8 \\
\hline $13-24$ & 61 & 16.4 \\
\hline $25-60$ & 127 & 34.1 \\
\hline$>60$ & 80 & 21.5 \\
\hline \multicolumn{3}{|l|}{ Type of ARV treatment } \\
\hline Never had treatment & 113 & 30.4 \\
\hline Without PIs & 110 & 29.6 \\
\hline With PIs & 136 & 36.6 \\
\hline Other associations & 06 & 1.6 \\
\hline Not informed & 07 & 1.8 \\
\hline \multicolumn{3}{|l|}{ LDL* } \\
\hline Normal & 293 & 84.4 \\
\hline Borderline & 38 & 11.0 \\
\hline High & 16 & 4.6 \\
\hline \multicolumn{3}{|l|}{ Creatinine } \\
\hline Normal & 278 & 74.7 \\
\hline High & 94 & 25.3 \\
\hline \multicolumn{3}{|l|}{ Proteinuria } \\
\hline Negative & 323 & 86.8 \\
\hline Positive $(+1)$ & 40 & 10.8 \\
\hline Positive $(+2$ and +3$)$ & 09 & 2.4 \\
\hline Total & 372 & 100.0 \\
\hline
\end{tabular}

* 25 individuals had triglycerides levels higher than $400 \mathrm{mg} / \mathrm{dL}$

triglycerides, $52 \%$ of the individuals sampled presented normal levels, $20.2 \%$ presented borderline levels and $27.8 \%$ presented elevated levels. Among the latter two groups, $41.9 \%(31 / 74)$ and $58.9 \%(56 / 95)$, respectively, were receiving ARV treatment with PIs. Concerning the levels of HDL cholesterol, $57.1 \%$ of the sample were composed of individuals with levels below normal. There was a statistically significant association between the levels of total cholesterol and triglycerides and the use of the ARV treatment. This association was not found when the HDL cholesterol was evaluated (Table 2).

Association between the values of glucose, total cholesterol and
Table 2

Distribution of HIV positive individuals according to type of ARV treatment and glucose, total cholesterol, triglycerides and HDL cholesterol levels. August to November 2000

\begin{tabular}{|c|c|c|c|c|c|c|c|}
\hline \multirow{3}{*}{$\begin{array}{l}\text { Type of ARV } \\
\text { treatment }\end{array}$} & \multicolumn{5}{|c|}{$\begin{array}{l}\text { Biochemistry } \\
\text { Glucose }\end{array}$} & \multirow{3}{*}{$\chi^{2}$} & \multirow{3}{*}{$\mathrm{p}$ value } \\
\hline & \multicolumn{3}{|c|}{ Normal } & \multicolumn{2}{|c|}{ Elevated } & & \\
\hline & & $\mathrm{n}$ & $\%$ & $\mathrm{n}$ & $\%$ & & \\
\hline Never had ARV & & 112 & 99.1 & 01 & 0.9 & & \\
\hline Without PIs & & 103 & 93.6 & 07 & 6.4 & & \\
\hline With PIs & & 134 & 98.5 & 02 & 1.5 & & \\
\hline \multirow[t]{3}{*}{ Total } & & 349 & 97.2 & 10 & 2.8 & $*$ & $* *$ \\
\hline & \multicolumn{5}{|c|}{ Total Cholesterol } & & \\
\hline & \multicolumn{3}{|c|}{ Normal } & \multicolumn{2}{|c|}{ Elevated } & & \\
\hline Never had ARV & & 97 & 85.8 & 16 & 14.2 & & \\
\hline Without PIs & & 91 & 82.7 & 19 & 17.3 & & \\
\hline With PIs & & 99 & 72.8 & 37 & 27.2 & & \\
\hline \multirow[t]{3}{*}{ Total } & & 287 & 79.9 & 72 & 20.1 & 7.318 & 0.026 \\
\hline & \multicolumn{5}{|c|}{ HDL Cholesterol } & & \\
\hline & \multicolumn{3}{|c|}{ Normal } & \multicolumn{2}{|c|}{ Low } & & \\
\hline Never had ARV & & 46 & 40.7 & 67 & 59.3 & & \\
\hline Without PIs & & 51 & 46.4 & 59 & 53.6 & & \\
\hline With PIs & & 57 & 41.9 & 79 & 58.1 & & \\
\hline \multirow[t]{3}{*}{ Total } & & 154 & 42.9 & 205 & 57.1 & 0.815 & 0.665 \\
\hline & \multicolumn{5}{|c|}{ Triglycerides } & & \\
\hline & \multicolumn{2}{|c|}{ Normal } & Borderl & \multicolumn{2}{|c|}{ Elevated } & & \\
\hline Never had ARV & 79 & 69.9 & 19 & 15 & 13.3 & & \\
\hline Without PIs & 62 & 56.4 & 24 & 24 & 21.8 & & \\
\hline With PIs & 48 & 35.6 & 31 & 56 & 41.5 & & \\
\hline Total & 189 & 52.8 & 74 & 95 & 26.5 & 35.13 & $<0.001$ \\
\hline
\end{tabular}

$* \chi^{2}$ not calculated; ** $\mathrm{p}$ value undetermined

triglycerides and the potential confounding factors (independent variables):

Glycemia: At the univariate analysis we found no statistically significant association between glucose levels and gender (Fisher: $\mathrm{p}=$ $1.00)$ and age group $\left(\chi^{2}: \mathrm{p}=0.107\right)$.

Total cholesterol: Among the associations tested (sex, age-group, physical exercise, glucose levels, creatinine and proteinuria) it was found a statistically significant association between the levels of total cholesterol and age group of the patient $\left(\chi^{2}=4.235\right.$, p-value $\left.=0.040\right)$.

Triglycerides: Statistically significant association was found between the levels of triglycerides and gender $\left(\chi^{2}=17.12\right.$, $\mathrm{p}$-value $<$ $0.001)$, age group $\left(\chi^{2}=13.72\right.$, $\mathrm{p}$-value $\left.=0.001\right)$ and creatinine levels $\left(\chi^{2}=16.101, \mathrm{p}\right.$-value $\left.<0.001\right)$. The association with triglycerides was not significant for the following variables: physical exercise, glucose level and proteinuria.

Association between total cholesterol and triglycerides and the 


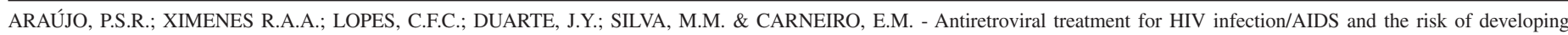
hyperglycemia and hyperlipidemia. Rev. Inst. Med. trop. S. Paulo, 49(2): 73-78, 2007.

type of antiretroviral treatment, adjusting for the potential confounding factors through a multiple logistical regression:

Total cholesterol: Adjusting for the effect of each other, the type of ARV treatment and age group by multiple logistical regression, it was found that the two variables remained in the model, indicating an independent association with each of them (Table 3) (The value of the maximum likelihood ratio for the removal of each of the variables was: Type of ARV treatment: maximum likelihood ratio $=6.093$, degree of freedom $=2, \mathrm{p}$ value $=0.0475$; Age group: maximum likelihood ratio $=3.398$; degree of freedom $=1 ; \mathrm{p}$ value $=0.0653$ )

Table 3

Odds Ratio for the association between total cholesterol and type of ARV treatment adjusted for age-group in HIV positive individuals

\section{CI $95 \%$}

\begin{tabular}{lcccc} 
Variables & Odds-ratio & Inferior & Superior & $\mathrm{p}$ value \\
\hline $\begin{array}{l}\text { Age group } \\
\quad<40 \text { years }\end{array}$ & 1.0000 & & & \\
$\quad>40$ years & 1.6801 & 0.9735 & 2.8994 & 0.0624 \\
$\begin{array}{l}\text { Type of ARV treatment } \\
\quad \text { Never had ARV }\end{array}$ & 1.0000 & & & \\
$\quad \begin{array}{l}\text { Treatment without PIs } \\
\quad 1.2255\end{array}$ & 0.5920 & 2.5370 & 0.5838 \\
$\quad$ Treatment with PIs & 2.1257 & 1.1033 & 4.0954 & 0.0242 \\
\hline
\end{tabular}

Triglycerides: To adjust the effect of each of the variables for each other through multiple logistical regression, the dependent variable, i.e., triglyceride levels, was transformed in a dychotomous variable: normal triglyceride/abnormal triglyceride (borderline triglyceride + elevated triglyceride). It was observed that all variables remained in the final model, indicating that they are independently associated with the triglyceride levels. (Table 4) (The value of the maximum likelihood ratio for the removal of each of the variables from the model was: Type of ARV treatment: maximum likelihood

Table 4

Odds Ratio for the association between triglycerides and type of ARV treatment, adjusted for age group, creatinine and gender in HIV positive individuals

\begin{tabular}{|c|c|c|c|c|}
\hline \multirow[b]{2}{*}{ Variables } & \multicolumn{4}{|c|}{ CI $95 \%$} \\
\hline & Odds-ratio & Inferior & Superior & $\mathrm{p}$ value \\
\hline \multicolumn{5}{|l|}{ Type of ARV treatment } \\
\hline Never had ARV & 1.0000 & & & \\
\hline Treatment without PIs & 1.6645 & 0.9406 & 2.9457 & 0.0802 \\
\hline Treatment with PIs & 3.5287 & 2.0274 & 6.1417 & $<0.0001$ \\
\hline \multicolumn{5}{|l|}{ Age group } \\
\hline$<40$ years & 1.0000 & & & \\
\hline$>40$ years & 2.0044 & 1.2193 & 3.2951 & 0.0061 \\
\hline \multicolumn{5}{|l|}{ Creatinine } \\
\hline Normal & 1.0000 & & & \\
\hline Elevated & 1.6775 & 0.9833 & 2.8619 & 0.0577 \\
\hline \multicolumn{5}{|l|}{ Sex } \\
\hline Female & 1.0000 & & & \\
\hline Male & 2.2360 & 1.3119 & 3.8110 & 0.0031 \\
\hline
\end{tabular}

ratio $=21.335$, degree of freedom $=2 ; \mathrm{p}$ value $<0.0001 ;$ Age group: maximum likelihood ratio $=7.624$, degree of freedom $=1, \mathrm{p}$ value $=$ 0.0058; Creatinine: maximum likelihood ratio $=3.632$, degree of freedom $=1, \mathrm{p}$ value $=0.0567$; Gender: maximum likelihood ratio $=$ 9.074 , degree of freedom $=1, \mathrm{p}$ value $=0.0026$ )

\section{DISCUSSION}

As a combination of at least three types of drugs including nucleoside reverse transcriptase inhibitors (NRTI), non-nucleoside reverse transcriptase inhibitors (NNRTI) and protease inhibitors (PIs), HAART is currently used to control the replication of HIV and AIDS.

Starting in 1995, with the first reports of the adverse effects of the initial representatives of the PI class, ritonavir, saquinavir and indinavir, several studies ${ }^{3,8,10,11,12,21,23}$ have driven attention to the fact that these drugs have been associated with an abnormal fat redistribution syndrome, which can raise the cholesterol and triglycerides levels, as well as cause insulin resistance. The metabolic alterations resulting from HAART may also be present in patients receiving regimens containing NRTI without the use of PIs, especially with stavudine. This suggests that PIs may not be the only ARV agents implicated in these alterations. The finding of relative risk of 1.95 of developing lipid redistribution in groups of patients receiving stavudine when compared to zidovudine after 14 months of treatment corroborates with this hypothesis ${ }^{19}$. A cohort study involving 277 participants ${ }^{14}$ evaluated the relative contributions of NRTIs and PIs as determinants of fat loss in patients infected with HIV. The study suggested that the NRTIs have an independent contribution toward the metabolic syndrome, but the PIs seem to be the main factors and probably act in synergy with the NRTIs. The nucleoside analogues seem to predispose the individuals to a slowly progressive fat loss that is markedly accelerated when a PI is combined to the ARV regimen.

Our results showed an increased chance of hypercholesterolemia and hypertriglyceridemia in patients receiving a PI-based antiretroviral regimen. Some aspects of our study deserve further comments. First, one of the characteristics that differentiates ours from most of other previous studies is the fact that we analyzed the potential confounding factors for hyperlipidemia, such as diabetes mellitus, primary hyperthyroidism, renal failure and nephrotic syndrome, which are recommended by the NCEP III, as well as gender, age group and the practice of exercise. Adjustment for these variables was performed, when indicated. Second, limitations of this work are related to the study design, cross-sectional, which does not include a period of followup and to the selection of patients. In relation to the ascertainment of patients, however, we have no reason to believe that there should be differences in the side effects of antiretroviral therapy between the patients in our study and those attending other health units in the same area. Moreover there are only three important reference units for HIV/ AIDS patients in the state of Pernambuco, and approximately $50 \%$ of the patients attend the out-patients clinics of Correia Picanço hospital.

The percentage of individuals who had an increase in their glucose levels was small $(n=10)$, which make comparisons difficult. It was observed a greater frequency (7/103) of individuals with elevated glucose levels among patients undergoing ARV treatment without PIs, whereas found just $1.5 \%(2 / 134)$ of patients with elevated glucose levels 
among the patients receiving PIs, but the small number limit our conclusions. There is, however, disagreement between these findings and those found in the literature, as a study carried out in 1999 describes an increase in the frequency of hyperglycemia among men receiving ARV therapy combined with PIs when compared to ARV regimens without these drugs ${ }^{15}$. In a five-year cohort study, HIV positive patients had plasma lipids monitored before and after the introduction of ARV with PIs. The effects of these drugs on cholesterol and triglyceride levels were much more frequent and important than on the glucose levels ${ }^{22}$.

In the sample of 372 patients, $113(30.4 \%)$ had never undergone ARV treatment, and $246(66.2 \%)$ were undergoing a regimen of a combination of drugs for at least six months. This is a length of time long enough for the development of metabolic alterations related to the ARV treatment, as an elevation in the levels of total cholesterol and triglycerides associated with the use of PIs may occur within the first weeks of treatment ${ }^{6}$. In patients receiving a PI-containing ARV regimen, the frequency of hypercholesterolemia was $27.2 \%$, and of hypertriglyceridemia was $41.5 \%$ ( $<<0.001)$, these values being significantly higher than in patients never treated with ARV regimens. Concerning the HDL levels, we found similar results in both groups of patients undergoing ARV treatment.

The association between increased levels of total cholesterol and triglycerides and the PI-based antiretroviral regimens is also referred by other authors. A prospective study with 239 patients described the extent and time course of the PIs effects on serum lipid levels of 148 patients receiving a triple combination ARV therapy including PIs, compared with a control group of 91 patients on therapy with two nucleosides. In the group receiving PIs the authors found a statistically significant increase in the total cholesterol after three, six and 12 months ( $\mathrm{p} \leq 0.001, \mathrm{p} \leq 0.001$ and $\mathrm{p} \leq 0.001$, respectively) in comparison to the baseline level recorded before the beginning of the ARV treatment, and an increase of $25.5 \%(\mathrm{p}=0.001)$ in the triglyceride levels from the baseline at month 3 . There was no change in the lipid levels in the control group ${ }^{20}$. In another cohort study, investigating 113 patients receiving ARV treatment with PIs (mean 21 months) and 45 patients infected with HIV that had never undergone ARV treatment with PIs, the authors observed a prevalence of hyperlipidemia of $74 \%$ at the beginning of the study in the group treated with PIs and a prevalence of $28 \%$ among those that had never undergone ARV treatment with PIs. The authors also found an impaired glucose tolerance in $16 \%$ of PIs recipients and diabetes mellitus in $7 \%$. There was no statistically significant difference between the two groups throughout the study ${ }^{5}$. Other authors report an increase in the levels of total cholesterol and triglycerides in patients receiving PIs 48 weeks after the beginning of the ARV treatment, but with no significant change in the levels of HDL cholesterol ${ }^{17}$. Other authors refer a high frequency of women receiving the HAART regimen containing PIs that presented modifications in body shape and elevated levels of serum lipids associated to an increase in the risk of cardiovascular disease, when compared to a similar group of women receiving the HAART regimen, but without complaints of change in body shape ${ }^{7}$.

Besides the use of PIs, age group was shown to be independently associated with increased levels of cholesterol in our study; when adjusted for each other type of ARV treatment and age group remained in the logistic model. Regarding other potential confounders, gender, practice of exercise, glucose, creatinine and TSH levels, and the presence of proteinuria were not associated with hypercholesterolemia.

Concerning triglycerides levels, the type of ARV treatment, gender, age group and creatinine level emerged as significantly and independently associated with increased triglycerides in the logistic regression model. On the other hand no association was found between hypertriglyceridemia and the practice of exercise, glucose level, proteinuria and the increase of TSH and the presence of proteinuria.

Prospective studies have only evaluated the influence of clinical signs that are suggestive of nephropathy or hypothyroidism in patients receiving ARV therapy with PIs. They did not find an association between the plasma lipid levels and the TSH levels, nor with the clinical condition of nephropathy, concluding that it is unlikely the nephrotic syndrome or hypothyroidism might have induced the observed lipid abnormalities, which corroborates with the findings in this study ${ }^{16}$.

Information regarding diet could not be analyzed in this study, despite having recorded the 24-hour dietary intake at the time of collecting the blood sample. It was not possible, therefore, to determine the potential contribution of dietary habits on the increase of the plasma lipid levels observed in some of the individuals during the study period.

Considering the profile of associated metabolic abnormalities and the number of years during which HIV positive patients will be exposed to ARV therapy, it is possible to anticipate the significant impact hyperlipidemia will have on the health of these individuals ${ }^{13}$.

The findings in this study indicate the need for a continuous monitoring of HIV seropositive patients in ARV therapy, especially those using PIs, for corrections whenever possible of metabolic alterations in an attempt to alleviate the adverse effects of these drugs on the health of these individuals. The findings recommend carrying out well-controlled cohort studies for the evaluation of the long-term consequences of HAART-associated hyperlipidemia; special focus on the risk of cardiovascular diseases should be given.

\section{RESUMO}

\section{Tratamento antiretroviral para a infecção pelo HIV/AIDS e o risco de desenvolver hiperglicemia e dislipidemia}

Um estudo epidemiológico transversal, com caráter analítico, foi realizado para descrever características sócio-demográficas bem como verificar a associação entre o tipo de tratamento antiretroviral empregado e hiperglicemia e hiperlipidemia, com especial atenção aos pacientes em uso de inibidores da protease do HIV. As informações foram obtidas a partir de um questionário e da coleta de sangue e urina para a execução dos exames laboratoriais. Foram entrevistados 418 pacientes, sendo que 46 indivíduos foram excluídos do estudo. A amostra foi então composta por 372 pacientes soropositivos para o HIV atendidos no ambulatório do Hospital Correia Picanço da Secretaria Estadual de Saúde, no período de agosto a novembro de 2000. O teste do Qui-quadrado foi usado para testar as associações e a regressão logística múltipla para ajustar pelos potenciais fatores de confusão. Observou-se uma maior frequência de pacientes com níveis 


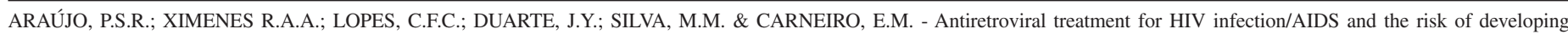
hyperglycemia and hyperlipidemia. Rev. Inst. Med. trop. S. Paulo, 49(2): 73-78, 2007.

elevados de glicose entre aqueles que faziam uso de terapia antiretroviral sem inibidores da protease, mas o pequeno número de indivíduos limitou as comparações. Verificou-se uma associação entre o colesterol total e o uso de inibidores da protease $(\mathrm{p}=0,047)$ mesmo após o ajuste por idade. Verificou-se também uma associação entre os níveis de triglicerídeos e o uso de inibidores da protease que permaneceu estatisticamente significante mesmo após o ajuste por idade, sexo e níveis de creatinina $(\mathrm{p}<0,001)$. Os níveis de glicose, de TSH, a presença de proteinúria e a pratica de exercícios físicos não estiveram associados com os níveis de colesterol ou com os níveis de triglicerídeos, não se caracterizando como fatores de confusão das associações descritas.

\section{REFERENCES}

1. BANDEIRA, F.; MACEDO, G.; CALDAS, G.; GRIZ, L. \& FARIA, M. - Diabetes mellitus tipo 2. In. Rio de Janeiro, MEDSI, 1998. p. 151-161. ndocrinologia. Diagnóstico e tratamento.

2. BARTLETT, J.G. - Toxicity of antiretroviral agents. Hopkins HIV Rep., 11: 2-12,1999.

3. CARR, A. \& COOPER, D.A. - Images in clinical medicine. Lipodystrophy associated with an HIV-protease inhibitor. New Engl. J. Med., 339: 1296, 1998.

4. CARR, A.; SAMARAS, K.; CHISHOLM, D.J. \& COOPER, D.A. - Pathogenesis of HIV1-protease inhibitor-associated peripheral lipodystrophy, hyperlipidaemia, and insulin resistance. Lancet, 351: 1881-1883, 1998.

5. CARR, A.; SAMARAS, K.; THORISDOTTIR, A. et al. - Diagnosis, prediction, and natural course of HIV-1 protease-inhibitor-associated lipodystrophy, hiperlipidaemia, and diabetes mellitus: a cohort study. Lancet, 353: 2093-2099, 1999.

6. CHURCHILL, D.R.; PYM, A.S.; BABIKER, A.G.; BACK, D.J. \& WEBER, J. N. Hyperlipidaemia following treatment with protease inhibitors in patients with HIV1 infection. J. Clin. Pharmacol., 46: 518-519, 1998.

7. DONG, K.L.; BAUSSERMAN, L.L.; FLYNN, M.M. et al. - Changes in body habitus and serum lipid abnormalities in HIV-positive women on highly active antiretroviral therapy (HAART). J. Acquir. Immune Defic. Syndr., 21: 107-113, 1999.

8. DUBÉ, M.P.; JOHNSON, D.L.; CURRIER, J.S. \& LEEDOM, J.M. - Protease inhibitorassociated hyperglycaemia. Lancet, 350: 713-714, 1997.

9. GERVASONI, C.; RIDOLFO, A.L.; TRIFIRÒ, G. et al. - Redistribution of body fat in HIV-infected women undergoing combined antiretroviral therapy. AIDS, 13: 465 471, 1999.

10. HENGEL, R.L.; WATTS, N.B. \& LENNOX, J.L. - Benign symmetric lipomatosis associated with protease inhibitors. Lancet, 350: 1596, 1997.
11. HERRY, I.; BERNARD, L.; TRUCHIS, P. \& PERRONNE, C. - Hypertrophy of the breasts in a patient treated with indinavir. Clin. infect. Dis., 25: 937-938, 1997.

12. LO, J.C.; MULLIGAN, K.; TAI, V.W.; ALGREN, H. \& SCHAMBELAN, M. - "Buffalo hump" in men with HIV-1 infection. Lancet, 351: 867-870, 1998.

13. MAGRO, D.O.; MORAES, M.J.; MOREIRA-FILHO, D.C. \& PEDRO, R.J. - Lipodistrofia e dislipidemia na infecção pelo HIV/AIDS. Uma breve revisão. J. bras. AIDS, 1: 14-18, 2000.

14. MALLAL, S.A.; JOHN, M.; MOORE, C.B.; JAMES, I.R. \& McKINNON, E.J. Contribution of nucleoside analogue reverse transcriptase inhibitors to subcutaneous fat wasting in patients with HIV infection. AIDS, 14: 1309-1316, 2000.

15. MAUSS, S.; WOLF, E. \& JAEGER, H. - Impaired glucose tolerance in HIV-positive patients receiving and those not receiving protease inhibitors. Ann. intern. Med., 130: $162-163,1999$.

16. PERIARD, D.; TELENTI, A.; SUDRE, P. et al. - Atherogenic dyslipidemia in HIVinfected individuals treated with protease inhibitors. The Swiss HIV cohort study. Circulation, 100: 700-705, 1999.

17. ROBERTS, A.D.; MUESING, R.A.; PARENTI, D.M. et al. - Alterations in serum levels of lipid and lipoproteins with indinavir therapy for human immunodeficiency virusinfected patients. Clin. infect. Dis., 29: 441-443, 1999.

18. SAFRIN, S. \& GRUNFELD, C. - Fat distribution and metabolic changes in patients with HIV infection. AIDS, 13: 2493-2505, 1999.

19. SAINT-MARC, T.; PARTISANI, M.; POIZOT-MARTIN, I. et al. - A syndrome of peripheral fat wasting (lipodystrophy) in patients receiving long-term nucleoside analogue therapy. AIDS, 13: 1659-1667, 1999.

20. SEGERER, S.; BOGNER, J.R.; WALLI, R.; LOCH, O. \& GOEBEL, F.-D. Hyperlipidemia under treatment with proteinase inhibitors. Infection, 27: 77-81, 1999.

21. SULLIVAN, A.K. \& NELSON, M.R. - Marked hyperlipidaemia on ritonavir therapy. AIDS, 11: 938-939, 1997.

22. TSIODRAS, S.; MANTZOROS, C.; HAMMER, S. \& SAMORE, M. - Effects of protease inhibitors on hyperglycemia, hyperlipidemia, and lipodystrophy: a 5-year cohort study. Arch. intern. Med., 160: 2050-2056, 2000.

23. VIRABEN, R. \& AQUILINA, C. - Indinavir-associated lipodystrophy. AIDS, 12: 37 $39,1998$.

Received: 18 September 2003

Accepted: 18 September 2006 